\title{
Editorials
}

\section{Making research matter}

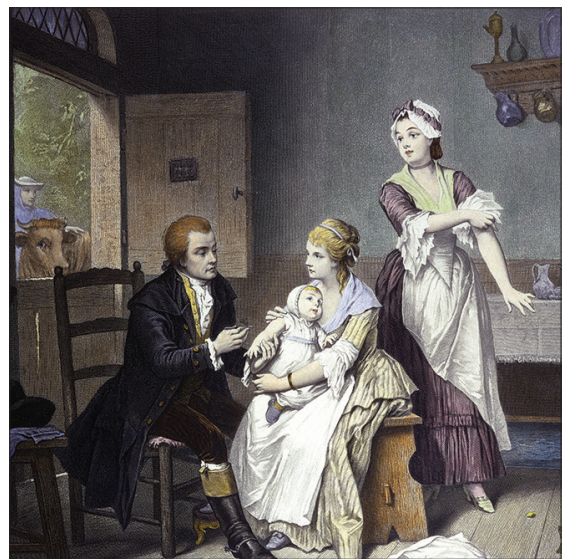

\section{INTRODUCTION}

The truth, according to Oscar Wilde, is rarely pure and never simple. In The Importance of Being Earnest, Wilde's character goes on to say that, were it not so, modern life would be very tedious and modern literature a complete impossibility.

Algernon might have inserted 'medical' between modern and literature: biomedical publication over the past 200 years is littered with outdated or discredited discoveries, false dawns, misapprehensions, and scientific fraud. The brilliant discoveries of yesterday have often become the curiosities of the current day, in fields as disparate as particle physics, cell biology, and cancer studies. Thomas Wakley, the great founding editor of The Lancet and, in my view, the father of evidence-based medicine (EBM), emphasised the need to disseminate best practice and to expose quackery and incompetence, when the first edition was published in the early 19th century. In the 20th century Archie Cochrane and subsequently the Cochrane Collaboration have rightly insisted on the rigorous conduct and reporting of randomised controlled trials as the best way to identify the benefits and, of course, harms of medical treatments. Systematic reviews and meta-analyses have now been raised to near-religious status in the pantheon of the ultra-rationalism of EBM.

\section{PUBLICATION OF RESEARCH}

This puts journal editors in a bit of a fix. Individual published studies are the substrate, the grist to the mill of metaanalysis and almost always have to be published to get into a systematic review.
We often ask our editorial colleagues and peer reviewers land we often press our authors on this tool to help us decide why this particular study matters, how it fits in, what is its 'clinical message', and what impact might it have on practice? Yet, at least in the back of our minds we know that, with few exceptions, a single primary research study probably won't and probably shouldn't have a practice-changing effect. Confirmation is needed, testing out the new hypothesis and the new findings in different settings and in different populations. So, is my first responsibility to my authors to promote the 'key message' of the study to clinicians and others, who may be less expert in the particular field, to talk-up and even over-egg the headlines in press releases in the hope of increasing exposure and citation? Or is my responsibility to our readers to ensure that they don't run away with the idea that this is the last word on the subject and rush off to implement a new treatment or management strategy on the basis of an over-stated short summary written by someone with a journal to run? Potentially painful it may be, but this is the nub of the argument for post-publication peer review; not the social media trolling that brings no credit to anyone, but a cool appraisal of the weight of the paper, the quality of the conclusions, and the validity of the message for practice. The wind seems to have gone out of the sails of this movement lately, but it is still something to think about. The truth is rarely pure and never simple.

\section{PAPER SHORT, WEB LONG}

As the BJGP continues to expand its online publication of full research articles, and to further reduce the amount of text that summaries of research occupy in the print edition, these are not irrelevant considerations. The full article, thoroughly peer-reviewed, revised, redrafted, subedited, proofed, and polished sits in the medical ether; as good as our imperfect human efforts at science, imagination, writing, and judgement will allow. Down on Earth, in the paper BJGP that lands in your hallway at the beginning of each month, we provide little more than a signpost to these riches, by publishing an annotated abstract of the research, along with a link from the online version of the Journal to the full article. And we don't think this is enough. Writing commentaries on individual papers is, for the reasons already given, unsatisfactory and potentially misleading, but we want to make stronger links between research and practice and, in doing so, emphasise the importance of the development of a body of work published over a substantial period of time, which leads to the identification of genuinely practice-changing discoveries and recommendations. To do this we are going to publish a regular 'Research into Practice' series, emphasising the links between a sustained programme of investigation and publication and changes in clinical practice. The series starts this month with an article from Professor Tony Avery's department in the University of Nottingham on safe prescribing. Further Research into Practice articles will be published on childhood illness and musculoskeletal disorders and, we hope, on ethnicity and health, multimorbidity, and managing acute respiratory tract symptoms.

\section{RESEARCH IMPACT}

This innovation should, we believe, be of real value to practising clinicians, who will also become aware of the efforts being expended to continue to build the base for evidence-based primary care practice. It is in line with the new emphasis placed by the higher education funding councils a single primary research study probably won't and probably shouldn't have a practice-changing effect. Confirmation is needed, testing out the new hypothesis and the new findings in different settings and in different populations. 


\section{ADDRESS FOR CORRESPONDENCE}

Roger Jones

Royal College of General Practitioners, 30 Euston

Square, London NW1 2FB, UK.

E-mail: rjonesđrcgp.org.uk on research impact in their assessment of university departments' research activity: in the current Research Evaluation Framework assessment, which determines the amount of research-related funding higher education institutions will receive, 'impact' accounted for $25 \%$ of the weight of some research outputs. It is certainly in line with the continuing struggle to provide a sound evidence base for clinical practice, which stretches back to the publication of the first Lancet in 1823.

\section{CHANGING CLINICAL PRACTICE}

It is, perhaps, worth acknowledging that peer-reviewed publication, systematic reviews, meta-analyses, and accounts of research impact are not the only, and may not be the most powerful, factors causing doctors to change their clinical practice. The extent of the research literature on the implementation of research reflects the difficulties encountered in getting evidencebased innovations into clinical practice and the diversity of implementation strategies that have been devised and tested. In one study of GPs who had changed their behaviour, three distinct models of behaviour change emerged, which seemed to capture many of the forces at play in clinical decision making. The first of these was an accumulation model, in which the weight of evidence gradually built up until the doctor felt confident in its 'weight' and relevance to practice. The second, challenge model operated when routine behaviour was questioned, perhaps by another doctor in the practice revising a patient's treatment schedule. The third, continuity model was seen among doctors working at the early adopter' end of the diffusion of innovations spectrum, who were actively seeking evidence on which to base improvements in their practice. These changes were modulated by other factors such as cost pressures and the comprehensibility of the therapeutic action of the drugs involved, as well as experience with individual patients. These factors may well operate at different times for different doctors making different therapeutic decisions. It is clear, however, that 'evidence' is not always the most salient factor in any of them.

\section{RESEARCH INTO PRACTICE}

I hope that the Research into Practice series will contribute usefully to this mix, by providing readable, relevant, and succinct accounts of how a sustained programme of research has led to clinically relevant recommendations and innovations. I hope, too, that you will give us your feedback on the series, with suggestions on how we can best frame the wealth of research evidence being generated in primary care, and also suggest other topics for the series.

\section{Roger Jones,}

BJGP Editor, London.

\section{Provenance}

Freely submitted; not externally peer reviewed.

DOI: 10.3399/bjgp14X679534

\section{REFERENCE}

1. Armstrong D, Reyburn H, Jones R. A study of general practitioners' reasons for changing their prescribing behaviour. BMJ 1996; 312: 949-952. 